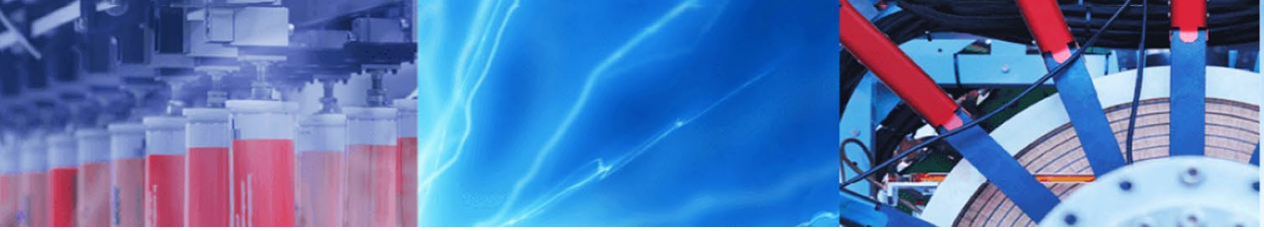

Research Article

\title{
Kinetic study of stereoselective synthesis of highly functionalized cyclopropane catalyzed by triphenylarsine
}

\author{
Mahdieh Darijani $^{1} \cdot$ Mehdi Shahraki $^{1} \cdot$ Sayyed Mostafa Habibi-Khorassani ${ }^{1}$
}

(c) Springer Nature Switzerland AG 2019

\begin{abstract}
A DFT method was used to enlighten the reaction mechanism between dimethylacetylendicarboxylate (DMAD) and acetylacetone (ACAC) in the presence of triphenylarsine (TPA) as an efficient catalyst. Different paths of mechanism and transition states with possible intermediates were proposed and evaluated thermodynamically and kinetically. The results showed that the reaction starts with a nucleophilic attack by the TPA on the DMAD, and then it was followed by other four steps. For all of the intermediates, Z conformer was more favorable than E conformer, and also the trans configuration of the product was more favorable than of cis configuration. Enol form of ACAC was more preferred than keto form in step ${ }_{4}$, but keto form was favorable for the other steps. For this reason, the reaction mechanism couldn't proceed through the enol-form, and the mechanism regarding keto-form of ACAC was the right mechanism. There were two possibilities for the proton-transferring step $_{4}$ which lead to different products. Trans di (methoxycarbonyl)-3,3-diacetylcyclopropane product 3, which was the result of 1, 3 non-linear proton-transfer arrangement and (Z)-Alkene dimethyl 2-(pentane-2,4-dione) fumarate (product 4) which was produced by 1,2 non-linear proton-transferring arrangement. Thermodynamic parameters exhibited that Z-Alkene is more stable than cyclopropane product, but cyclopropane product was more preferred kinetically $\left(\mathrm{E}_{\mathrm{a}}\right.$ trans cyclopropane $=44.75 \mathrm{kcal} \mathrm{mol}^{-1}, \mathrm{E}_{\mathrm{a}}$ Alkene $\left.=66.75 \mathrm{kcal} \mathrm{mol}^{-1}\right)$.
\end{abstract}

Keywords Kinetics $\cdot$ Conformer $\cdot$ Intermediates $\cdot$ Tautomerization $\cdot$ Fumarate

\section{Introduction}

Cyclopropanes moieties are used as important intermediates in the synthesis of more functionalized cycloalkanes and acyclic compounds. There are natural and synthetic cyclopropane compounds with biological activities such as antibacterial, antiviral, and antitumoral and also enzyme inhibition. In the structure of some drugs like Odanacatib, Singulair, and ciprofloxacin, cyclopropane groups are available. Cyclopropane includes in some important process such as cyclopropanation, ring-opening, cyclization or ring expansion. So these compounds are important building blocks in organic compounds synthesis.
Cyclopropane moiety with the electron-donating or the electron-withdrawing groups is importance intermediates in organic chemistry because these compounds imply a mild condition to the important synthesis of 1,3-zwitterionic intermediates which participate in various reactions. Stereo and enantioselective synthesis is an important subject to researchers. Commonly three methods are used to synthesis a stereoselective cyclopropane, and they are as follow: (1) transition-metal catalyzed the decomposition of diazo compounds; (2) Michael-initiated ring closure (MIRC) and; (3) the cyclopropanation of olefins with halomethyl metal reagents [1-8]. The stereoselective synthesis of di(methoxycarbonyl)-3,3-diacetylcyclopropane via the

Electronic supplementary material The online version of this article (https://doi.org/10.1007/s42452-019-0587-0) contains supplementary material, which is available to authorized users.

Mehdi Shahraki, mehdishahraki@chem.usb.ac.ir | ${ }^{1}$ Department of Chemistry, Faculty of Science, University of Sistan and Baluchestan, P. O. Box 98135-674, Zahedan, Iran.

SN Applied Sciences (2019) 1:553 | https://doi.org/10.1007/s42452-019-0587-0 
reaction between dimethylacetylendicarboxylate (DMAD) and acetylacetone (ACAC) was reported catalyzed by triphenylarsine (TPA) (Scheme 1) [9]. We have previously studied the kinetics of this reaction and compared to the presence of triphenylphosphine (TPP) as a catalyst [10]. TPA reacted as a stronger nucleophile and a catalyst, resulting in the fourth step of the reaction ( step $_{4}, k_{4}$, a proton transfer process) being recognized as the RDS. The reaction followed by second-order kinetics. The proposed mechanism was adapted in accord with the experimental results and the steady-state assumption. The results showed that the reaction rate decreases in the presence of $D B M$, which participates in the second step $\left(\operatorname{step}_{2}\right)$, compared to ACAC when it is present as another 1,3-dicarbonyl compound (structural effect). Also, the partial order of the reaction concerning the 1,3-dicarbonyl compound was one. As a significant result, not only did a change in the structure of one of the reactants (TPA instead of TPP) create a different product, but also the kinetics and reaction mechanism changed. Also, the $\Delta H^{\ddagger}$ term was much more significant than the $T \Delta S^{\ddagger}$ term, so the reaction was enthalpy-controlled. Detection of intermediates and types of probable forms with experimental techniques was not possible. It is also important to calculate thermodynamic and kinetic data to confirm the reaction mechanism and provides comprehensive information on each mechanism step. For this purpose, the reaction is studied kinetically and thermodynamically in the presence of triphenylarsine as a catalyst (TPA) using computational methods (Scheme 1) $[11,12]$. Different paths of mechanism and transition states with possible intermediates are proposed. We hope that these details will provide comprehensive information on the kinetics and mechanism of this reaction and modify existing methods.

\section{Computational methods}

All quantum chemical calculations including geometry optimization, normal mode vibrational frequencies calculations of the species $\left(1,2,3, I_{1}, I_{2}, I_{3}, I_{4}, P\right)$ in the reaction path was done using DFT method at B3LYP/6-31 + G(2d,p) [13-15] level of theory. Frequency calculations showed that TS coordination is a saddle point because of only one imaginary frequency and other species (with real frequency) are in a real minimum. The intrinsic reaction coordinates (IRC) [16] method was used to determine the TS structure for each step. All calculations were done using the Gaussian 09 program [17].

\section{Results and discussion}

The proposed mechanism is shown in Scheme 2. As can be seen, the mechanism involves five steps:

Step $p_{1}$ Nucleophilic attack between of TPA to DMAD and $\mathrm{I}_{1}$ formation.

Step $\mathrm{I}_{1}$ protonation by ACAC and production of $\mathrm{I}_{2}$ and ACAC $^{-}$.

Step ${ }_{3} \mathrm{I}_{3}$ production by the reaction of $\mathrm{I}_{2}$ and $\mathrm{ACAC}^{-}$, as two ions $\left(I_{2}\right.$ and $\left.A C A C^{-}\right)$, results in $I_{3}$.

Step $_{4} 1,3$ proton transfer in $I_{3}$.

$\mathrm{Step}_{5}$ Cyclopropane ring (product) formation.

At the first step, the product $\left(I_{1}\right)$ is generated as a zwitterionic intermediate which can be either in $\mathrm{E}$ or $\mathrm{Z}$ forms (Fig. 1). Therefore, there are two states for each step (E or $Z$ form) that are shown in Scheme S1 to S5 [Supplementary Information (SI)]. Also, the same challenge is for the remaining steps, therefore to identify the right conformation of the product species in the mechanism the potential energy profile investigated. For this reason in both $E$ and $Z$ forms, of each step (step ${ }_{1}$, step ${ }_{2}$, step $_{3}$, step ${ }_{4}$, and step ${ }_{5}$ ) the distance between the two reactant atoms leading to a stable bond scanned, and the transition state for each step determined. The related potential energy profiles are shown in Figure $\mathrm{S} 1$ to $\mathrm{S} 10$ for each step. The $\mathrm{E}$ form of $\mathrm{I}_{1}$ has a bigger energy barrier then $Z$ form, so the $Z$ form of $I_{1}$ is preferred. It should be mentioned that there are two transition states to reach $E$ form of $I_{1}$, first $I_{1 a(E)}$ formed through $\mathrm{TS}_{1 \mathrm{a}}$ and then $\mathrm{I}_{1 \mathrm{E}}$ formation happened through $\mathrm{TS}_{1 \mathrm{~b}}$. The total energy barrier for this process is $10.10 \mathrm{kcal} \mathrm{mol}^{-1}$, but for $Z$ formation we have just one TS with an energy barrier of $7.5 \mathrm{kcal} \mathrm{mol}^{-1}$. So $\mathrm{Z}$ formation is easier than $\mathrm{E}$. The potential energy profiles for the formation of cis and trans during the reaction path, involving six and five TS, respectively, cyclopropane obtained in the gas phase at the B3LYP/6-31 $+G(2 d, p)$ level of theory are presented in Fig. 1.
Scheme 1 The stereoselective synthesis of highly functionalized cyclopropane catalyzed by triphenylarsine

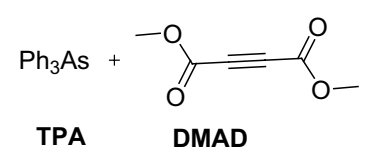

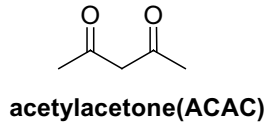

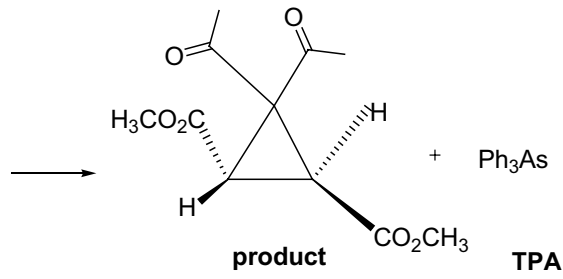



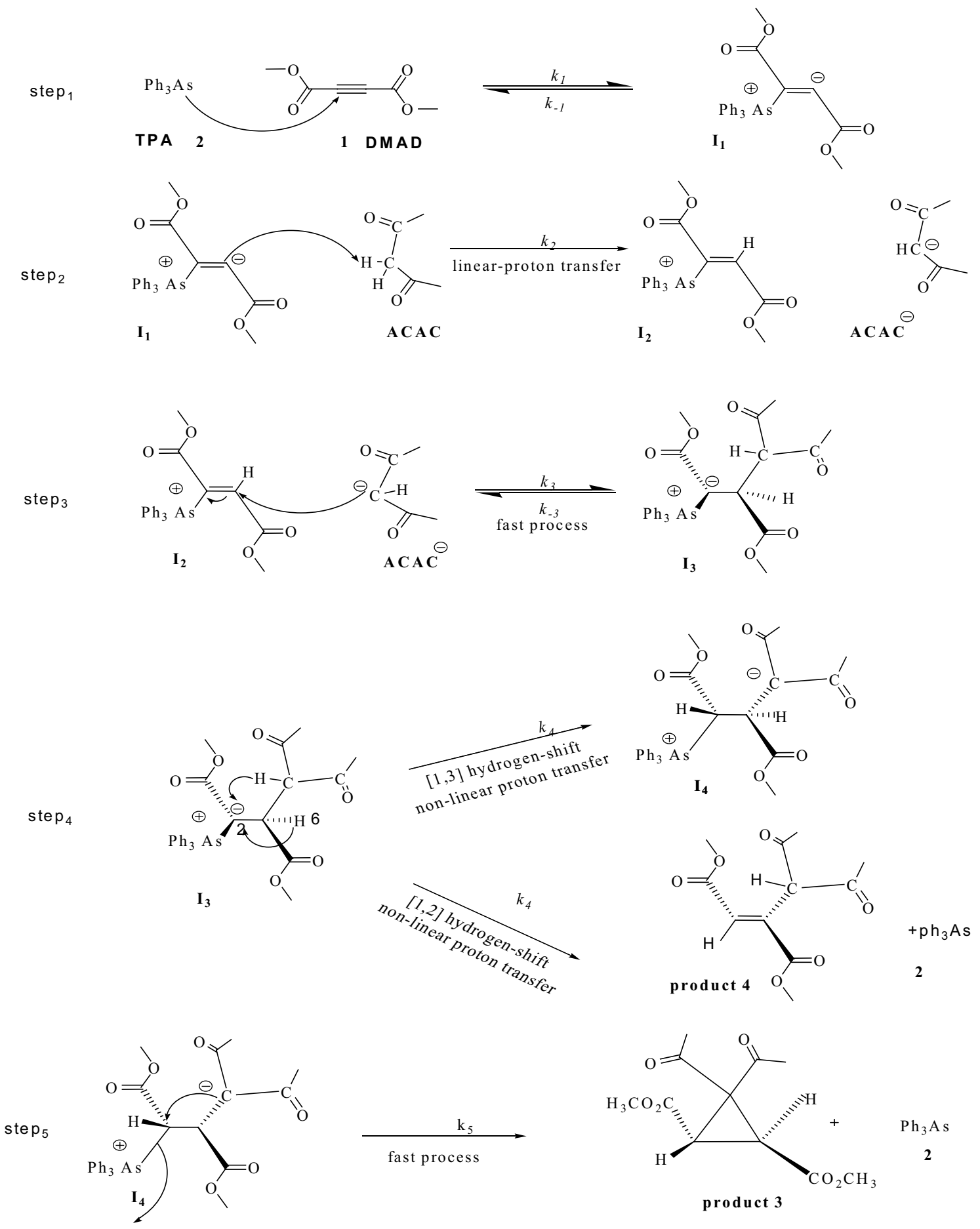

Scheme 2 The proposed reaction mechanism among triphenylarsine, DMAD and ACAC for the generation of product 4 and product 3

The cis and trans conformations of the final product 3 also investigated in the gas phase at B3LYP/6-31+G(2d,p) level of theory. Some selected geometry parameters for each step contributors are given in Table S1.

The kinetic and thermodynamic parameters for $\mathrm{E}$ and $Z$ forms of the species in the reaction mechanism are presented in Table 1. The $Z$ and $E$ forms comparison demonstrates that activation energy and it's parameters $\left(\Delta G^{\ddagger}\right.$, $\Delta \mathrm{H}^{\ddagger}$, and $\Delta \mathrm{S}^{\ddagger}$ ) are in favor of $\mathrm{Z}$ form than $\mathrm{E}$, so we have a bigger rate constant for $Z$ than $E$. Thus $Z$ form is preferred.

According to thermodynamic parameters, $\Delta G^{\circ}$ value indicates that all steps are exothermic except step $_{1}$ and 
Fig. 1 Schematic free energy diagram of the reaction mechanism at the B3LYP/6$31+G(2 d, p)$ level of theory for $\mathrm{Z}$ and $\mathrm{E}$ forms
Table 1 Kinetics and thermodynamic parameters of the speculative mechanism containing five, steps declined in $E$ and $Z$ forms of species at $B 3 L Y P / 6-31+G(2 d, p)$ level of theory

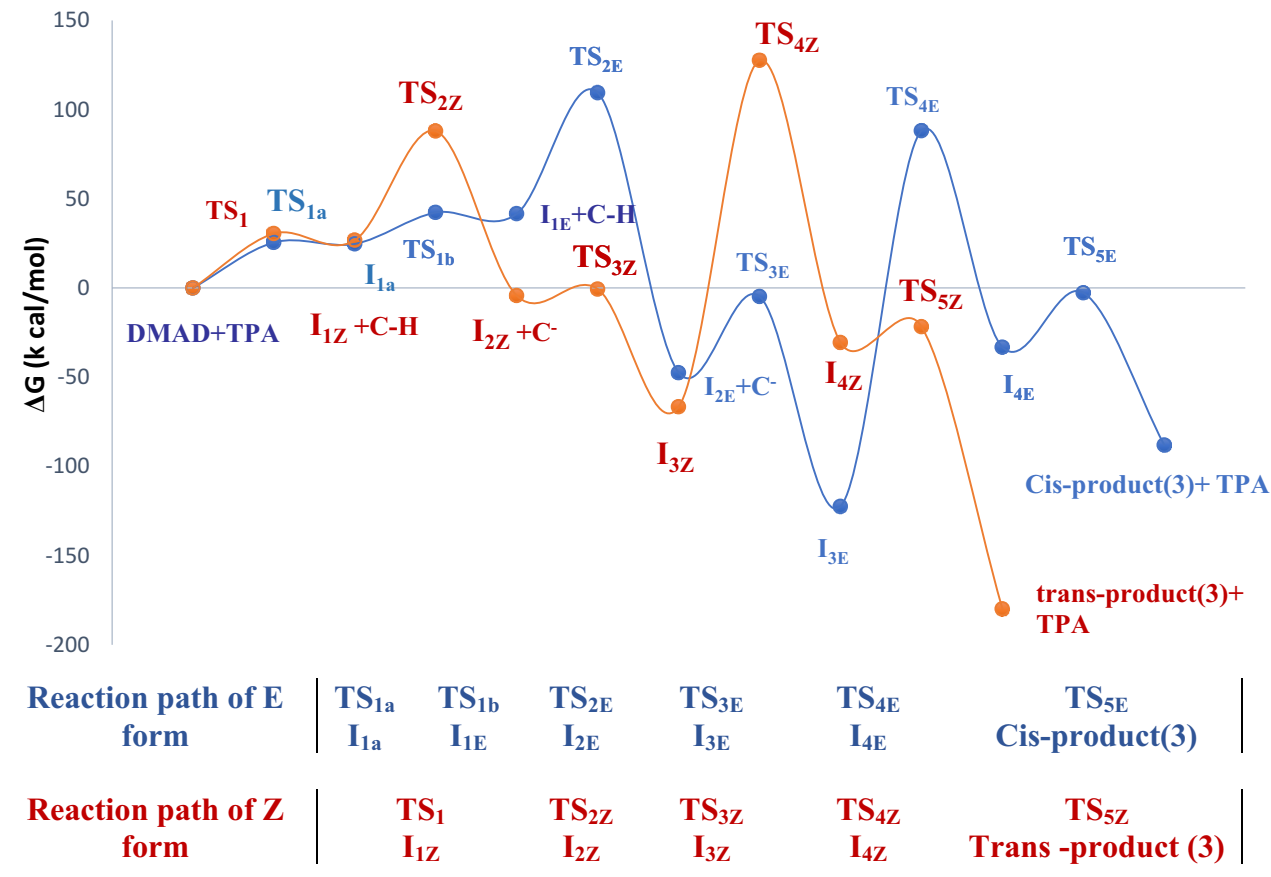

\begin{tabular}{|c|c|c|c|c|c|c|c|c|c|}
\hline & $\mathrm{k}_{\mathrm{n}}$ & $k_{-n}$ & $\mathrm{E}_{\mathrm{a}}$ & $\Delta \mathrm{G}^{\ddagger a}$ & $\Delta \mathrm{H}^{\ddagger a}$ & $\Delta \mathrm{S}^{\neq \mathrm{b}}$ & $\Delta \mathrm{G}^{\mathrm{oa}}$ & $\Delta \mathrm{H}^{\text {oa }}$ & $\Delta S^{o b}$ \\
\hline \multicolumn{10}{|c|}{ Step $_{1}$} \\
\hline$E$ & $4.04 \times 10^{-1}$ & $1.77 \times 10^{11}$ & 14.71 & 17.99 & 13.52 & -15 & 15.88 & 11.46 & 18.4 \\
\hline Z & $2.83 \times 10^{1}$ & $1.88 \times 10^{13}$ & 12.08 & 15.57 & 10.89 & -15 & 16.23 & 10.90 & -17 \\
\hline \multicolumn{10}{|c|}{ Step $_{2}$} \\
\hline$E$ & $1.97 \times 10^{-2}$ & $2.07 \times 10^{-2}$ & 15.51 & 19.77 & 14.32 & -18 & 0.03 & -5.05 & -17 \\
\hline Z & $2.08 \times 10^{-1}$ & $1.23 \times 10^{-1}$ & 14.24 & 18.38 & 13.06 & -17 & -0.31 & -4.18 & -13 \\
\hline \multicolumn{10}{|c|}{ Step $_{3}$} \\
\hline$E$ & $4.45 \times 10^{9}$ & $1.31 \times 10^{-8}$ & 6.22 & 3.93 & 5.04 & 3 & -24.26 & -22.66 & 5 \\
\hline Z & $4.45 \times 10^{10}$ & $1.79 \times 10^{-2}$ & 1.06 & 2.92 & 0.12 & -10 & -16.91 & -17.11 & -9 \\
\hline \multicolumn{10}{|c|}{ Step $_{4}$} \\
\hline$E$ & $1.82 \times 10^{-24}$ & $7.94 \times 10^{-18}$ & 48.01 & 49.83 & 40.78 & -10 & 9.05 & 6.57 & -8 \\
\hline Z & $1.32 \times 10^{-21}$ & $4.27 \times 10^{-11}$ & 44.75 & 45.93 & 43.57 & 7 & 14.33 & 12.50 & -6 \\
\hline \multicolumn{10}{|c|}{ Step $_{5}$} \\
\hline$E$ & $1.96 \times 10^{9}$ & $7.31 \times 10^{-8}$ & 7.49 & 4.77 & 6.30 & 11 & -22.41 & -17.41 & 17 \\
\hline Z & $5.59 \times 10^{11}$ & $5.49 \times 10^{-15}$ & 1.77 & 1.43 & 0.6 & 3 & -35.48 & -35.48 & 16 \\
\hline
\end{tabular}

$\mathrm{n}=1,2,3,4,5$

${ }^{\mathrm{a}}$ In kcal mol ${ }^{-1}$

${ }^{\mathrm{b}}$ In cal mol ${ }^{-1} \mathrm{~K}^{-1}$

step $_{4}$ in both $Z$ and $E$ forms. Step ${ }_{4}$ has the minimum rate constant and maximum energy of activation, so this step is the RDS. Moreover, step $_{5}$ is the fastest step among others, according to kinetic parameters reported in this Table. The thermodynamic parameters for the optimized $E$ and $Z$ structures of the all intermediates $\left(I_{1}, I_{2}, I_{3}, I_{4}\right)$ and product (3) calculated and the results are presented in Table S2. As can be understood, $Z$ form is preferred for all intermediates and product 4 and also a trans form of product 3 .
Table 2 shows the thermodynamic parameters of trans and cis forms of the product 3 , the more negative value of the thermodynamic parameters for trans form ensure us that $Z$ form of the product 3 is favorable thermodynamically, of course, product 4 ( $Z$ form) will be discussed next.

The thermodynamic energy of 1, 2 intermolecular proton shift for the $Z$ form of $I_{3}$ in step ${ }_{4}$ was calculated and the energy profile is shown in Figure $\mathrm{S} 11$. The transition state was obtained by scanning the bond length between $\mathrm{H}_{6}$ 
Table 2 Gibbs free energy, enthalpy and entropy of cis and trans forms of the cyclopropane (product 3) calculated at the B3LYP/6$31+\mathrm{G}(2 \mathrm{~d}, \mathrm{p})$ Level at $298 \mathrm{~K}_{\text {in kcal mol}}^{-1}$ and cal mol $\mathrm{K}^{-1}$, respectively

\begin{tabular}{lccc}
\hline & $\Delta_{\mathrm{r}} \mathrm{G}_{\text {total }}^{0}$ & $\Delta_{\mathrm{r}} \mathrm{H}_{\text {total }}^{0}$ & $\Delta_{\mathrm{r}} \mathrm{S}_{\text {total }}^{0}$ \\
\hline Trans-product 3 & -27.42 & -34.47 & -23.67 \\
Cis-product 3 & -16.43 & -21.16 & -15.87 \\
\hline
\end{tabular}

and $\mathrm{C}_{2}$ (Scheme 2). The results exhibited that in this process, the proton transferring $\left(\mathrm{H}_{6}\right)$ and the leaving group (triphenylarsine, catalyst) is concerted, and product 4 can be produced in this step. To comprise the energy barrier of product 4 (the result of $1,2 \mathrm{H}$-shifted) and product 3 (the result of 1,3 proton shift) it's cleared that product 4 with the energy barrier of $66.75 \mathrm{kcal} \mathrm{mol}^{-1}$ is more stable than product 3 (with the energy barrier of 44.75 ), so product 4 is thermodynamically-controlled.

\subsection{Keto and enol forms of acetylacetone}

If we look at carefully to the reaction mechanism in Scheme 2. It will be understood that the exception of step $_{1}$, ACAC moiety has been contributed to other steps (containing step $_{2}$, step $_{3}$, step $_{4}$ ).

The question is, which form of ACAC, enol-or-keto form, can be participated in the reaction mechanism, particular step ${ }_{2}$, step ${ }_{3}$, and step $_{4}$. To answer this, keto-enol tautomerization of acetylacetone (ACAC) was regarded to find out the right tautomer in the reaction mechanism. For this reason, the geometry optimization of both forms carried out using B3LYP/6-31 +G $(2 d, p)$ level of theory. The thermodynamic parameters $\left(\mathrm{G}^{\circ}, \mathrm{H}^{\circ}, \mathrm{S}^{\circ}\right)$ of keto and enol forms of $A C A C$ and $A C A C^{-}$, respectively, are shown in Table S3. The details can be explained. Clearly; the recorded result in Table S3 indicated that keto form could exist as the two enol form; Enol-ACAC 1 and Enol-ACAC ${ }_{2}$, rows 2 and 3, respectively. It was realized that Enol-ACAC 1 is more stable.

When keto form of ACAC losses a proton, it converted to $A C A C^{-}$form. This form can be found at the five forms; keto$\mathrm{ACAC}_{1}{ }^{-}$, keto-ACAC ${ }_{2}{ }^{-}$, Enol-ACAC ${ }_{1}^{-}$, Enol-ACAC ${ }_{2}{ }^{-}$and Enol$\mathrm{ACAC}_{3}{ }^{-}$, rows $4,5,6,7$ and 8 , respectively. The recorded results in Table $\mathrm{S} 3$ exhibited that most stable form among various $A C A C^{-}$form is keto- $A C A C_{1}^{-},\left(G^{\circ}\right.$, row 4$)$ and among $A C A C$ form is Enol-ACAC ${ }_{1}^{-}\left(G^{\circ}\right.$, row 2$)$. The reaction mechanism, regarding enol form of ACAC for steps 2,3 and 4 is shown in Scheme 3, respectively.

In the proposed mechanism [9], in Scheme 2 keto form of ACAC starts the reaction, but theoretical studies on the keto and enol forms of ACAC confirmed that enol form is more stable than keto energetically. Therefore to examine exactly which form of ACAC take place in the reaction, the energy profile of the reaction in the case of enol form investigated at B3LYP/6-31 $+G(2 d, p)$ of theory. As shown in the mechanism, in the case of enol form of ACAC (enol$A C A C_{1}$ ) two pathways are possible for proton donation to $\mathrm{I}_{1}$, Scheme 3-pathway A, and Scheme 4-pathway B.

\subsection{Reaction mechanism investigation in the presence of enol or keto form}

\subsubsection{Pathway A}

Scheme 3 demonstrates the reaction mechanism in the case of $\mathrm{H}_{\mathrm{A}}\left(\mathrm{H}_{1}\right)$ transferring (subscript A refers to the pathway). To obtain the TS structure, the distance between $\mathrm{C}_{3}-\mathrm{H}_{1}$ was scanned $\left(\right.$ step $\left._{2}\right)$. The potential energy profile of the step $\mathrm{P}_{2}$ is shown in Figure S12. Optimization of $I_{1}$ and ACAC shows that unusually $\mathrm{ph}_{3} \mathrm{As}$ should be separated from DMAD, then after proton transferring $\left(\mathrm{H}_{1}\right)$ the $\mathrm{ph}_{3}$ As will be attached again, and $\mathrm{I}_{2}$ generates (by passing through $\mathrm{TS}_{2}$ ). The optimized geometries of the species in step ${ }_{2}$ are illustrated in Fig. 2. Then, in step ${ }_{3}$ ACAC $2^{-}$attacks to $\mathrm{I}_{2}$ (Scheme 2 ) and $\mathrm{C}_{3}-\mathrm{O}$ bond will be formed between $\mathrm{ACAC}_{2}{ }^{-}$and $\mathrm{I}_{2}$ for unfavorable product $\left(\mathrm{I}_{3}\right)$ with higher energy barrier instead of $\mathrm{C}_{3}-\mathrm{C}_{4}$ bond formation, for deserve Trans-product (3), shown in Scheme 2, so the remaining steps will not proceed, and this pathway should be discarded.

\subsubsection{Pathway B}

Scheme 4 exhibits the mechanism in the case of $\mathrm{H}_{B}$ transferring $\left(\mathrm{H}_{2}\right)$. Herein, in step $\mathrm{p}_{2}$ the potential energy profile demonstrated, the proton $\left(\mathrm{H}_{2}\right)$ transferring for $\mathrm{C}_{3}-\mathrm{H}_{2}$ bond formation and $\mathrm{C}_{3}-\mathrm{C}_{4}$ bond formation between $\mathrm{ACAC}^{-}$and $\mathrm{I}_{2}$ is concerted and appears as one step, and step $\mathrm{P}_{3}$ did not exist as shown in Fig. 3. The potential energy profile for transferring $\mathrm{H}_{2}$ to $\mathrm{C}_{3}$ is shown in Figure $\mathrm{S} 13$.

The energy barrier for the concerted reaction in the step $_{2}$ of pathway $B$ that eliminated step ${ }_{3}$ to form $\left(I_{3}\right)$ is more than the sum of energy barrier in step $_{2}$ and step $_{3}$ in the case of keto form of ACAC (see step $_{2}$ and step $\mathrm{p}_{3}$ in Scheme 2). The geometry of optimized structures for the species in step 2enol $_{1}\left(I_{1}+A C A C_{\text {enol, }}, T_{2}, I_{3}\right)$ is shown in Fig. 3. Following step $\left(\right.$ step $\left._{4}\right)$ is proton-transferring from $\mathrm{O}_{3}$ to $\mathrm{C}_{5}$. The distance between $\mathrm{H}_{1}$ and $\mathrm{C}_{5}$ is so much for proton transfer. There is a geometrical restriction for this step, so the molecule changes it's carbonyl direction to form $\mathrm{I}_{3 a}$ (Fig. 4) by an energy barrier of $60 \mathrm{kcal} \mathrm{mol}^{-1}$ to simplify 1 , 5 proton transfer within the energy barrier of $5 \mathrm{kcal} \mathrm{mol}^{-1}$ as shown in Figure S14. This process (1, 5 proton transfer) consists of two steps with a total energy barrier of $65 \mathrm{kcal} \mathrm{mol}^{-1}$. To sum up, the energy barrier for the reaction in pathway $B$ is too high $\left(90 \mathrm{kcal} \mathrm{mol}^{-1}\right)$, so the reaction can't proceed from the enol form. According to the 
results, $\mathrm{H}_{2}$ transferring is possible by the concerted reaction and lead to the product by passing through a difficult route, so the reaction mechanism regarding keto form of $A C A C$ is the right mechanism.

\subsection{Tautomerization of $\mathrm{I}_{3}$}

Another possibility for the reaction is the conversion of keto form of $\mathrm{I}_{3}$ to enol, and the 1,5 proton-shift process occurs to make $\mathrm{I}_{4}$ and subsequently the trans-product, Scheme 5. The energy barrier for the keto-enol conversion $\left(\right.$ step $\left._{\text {keto-enol }}\right)$ is too high, but the proton transfer process needs a little energy to proceed (see Figure S15 and S16).

Kinetics and thermodynamic parameters for these steps are reported in Table 3. According to the results, keto-enol conversion step has the highest energy barrier $\left(61.2 \mathrm{kcal} \mathrm{mol}^{-1}\right)$ and 1,5 proton-transfer in step 4 has the less energy barrier $\left(5.2 \mathrm{kcal} \mathrm{mol}^{-1}\right)$ among other steps in the case of enol form. So step keto-enol can be regarded as RDS. The energy barrier for this route is too high so the reaction can't proceed through this mechanism.

Table 3 kinetic parameters (rate constant, the energy of activation and Gibbs free energy) of step keto-enol $_{\text {and }}$ step $_{4}$ for tautomerization in $I_{3}$ at $B 3 L Y P / 6-31+G(2 d, p)$ level of theory

\begin{tabular}{llrr}
\hline & $k^{\mathrm{b}}$ & $\mathrm{Ea}^{\mathrm{a}}$ & \multicolumn{1}{c}{$\Delta \mathrm{G}^{\ddagger \mathrm{a}}$} \\
\hline Step $_{\text {keto-enol }}\left(\mathrm{I}_{3 \text { enol }}\right)$ & $2.8 \times 10^{-35}$ & 61.2 & 64.6 \\
Step $_{4}\left(\mathrm{I}_{4}\right)$ & $3.0 \times 10^{9}$ & 5.2 & 4.5 \\
\hline
\end{tabular}

${ }^{\mathrm{a}} \mathrm{kcal} \mathrm{\textrm {mol } ^ { - 1 }}$

${ }^{\mathrm{b}} \mathrm{S}^{-1}$

\section{Conclusion}

A Theoretical kinetics investigation carried out at the B3LYP/6-31 + G $(2 d, p)$ level of theory to determine the mechanism, RDS and the real path in the reaction among DMAD, triphenylarsine, and acetylacetone (ACAC) for the generation of Trans-cyclopropane product (3).

The results are summarized as follow:

1. Reaction proceeds in five steps and step $_{4}$ are RDS.

2. The overall reaction is exothermic and a spontaneous process.

3. The intermediates in the reaction path prefer $Z$ form than $\mathrm{E}$.

4. The reaction is kinetically-controlled, and the product is trans cyclopropane

5. $I_{1}$ formation in the $\operatorname{step}_{1}$ can be generated through the two reaction paths. The reaction path leads to $Z$ conformer has one transition state with the energy barrier of $\left(7.5 \mathrm{kcal} \mathrm{mol}^{-1}\right)$, and $\mathrm{E}$ conformer needs a path through the two transition states with the energy barrier of $10.10 \mathrm{kcal} \mathrm{mol}^{-1}$. It seems that the stereoselectivity of the reaction originates from step . $_{1}$

6. Consideration of keto-enol tautomerization of ACAC in the reaction mechanism (for five steps) exhibited that in step ${ }_{4}$ enol form of ACAC is only preferred, and in the other steps keto form is favorable. Therefore, theoretical calculations indicated that examining of enol form instead of keto form of acetylacetone (ACAC) during the reaction path containing pathway $A$ and tautomerization of some intermediates as enol forms proceed

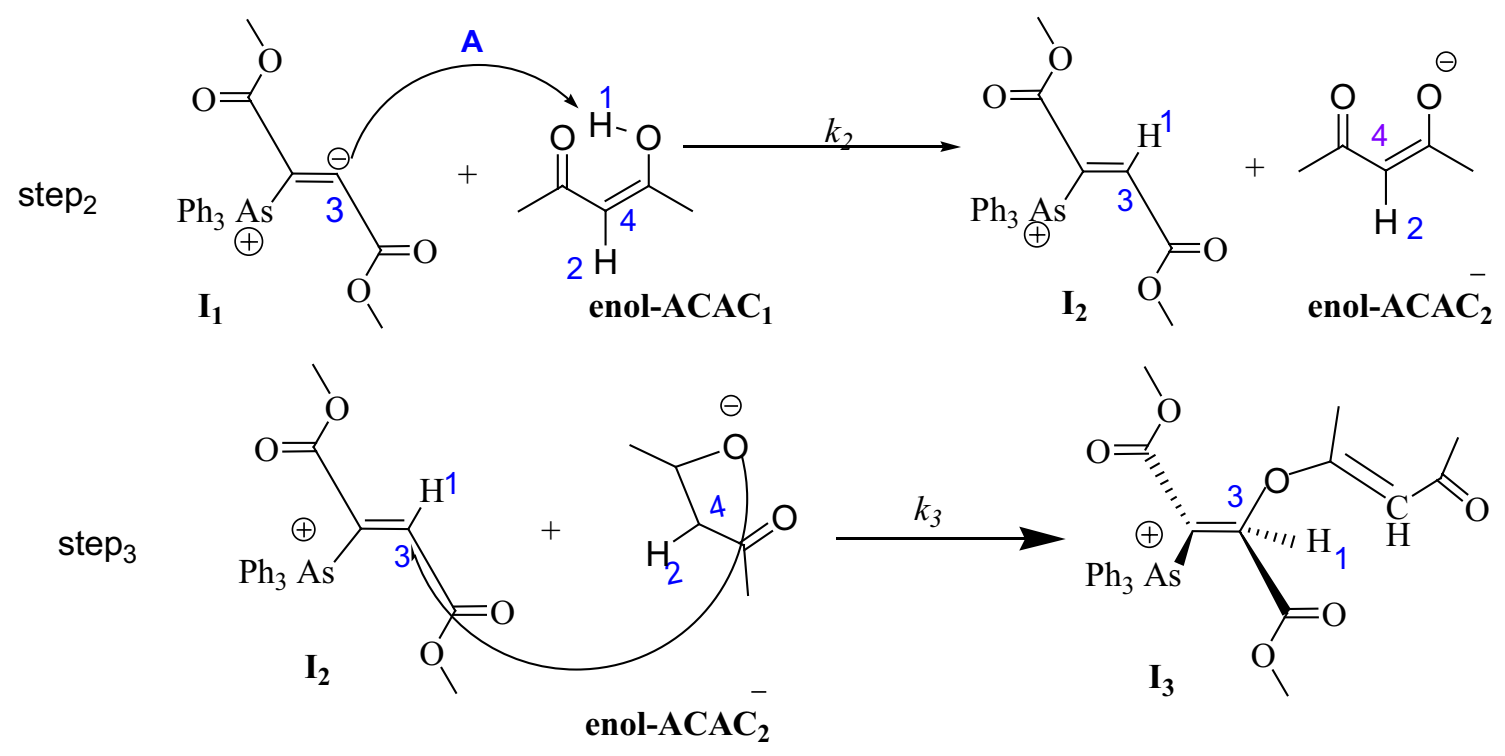

Scheme 3 The proposed reaction mechanism about the enol form of ACAC (enol-ACAC $)$ in pathway $A$ 
Scheme 4 The proposed reaction mechanism about the enol form of ACAC (enol-ACAC $\left.{ }_{1}\right)$ in pathway $B$
Fig. 2 The optimized structures of $\mathrm{I}_{2}, \mathrm{TS}_{2}$ and $\mathrm{I}_{3}$ in pathway $\mathrm{A}$<smiles>COC(=O)C(=O)C(=O)OC</smiles>

step3<smiles>CCCCC(=CC(=O)OC)C(=O)OC</smiles>

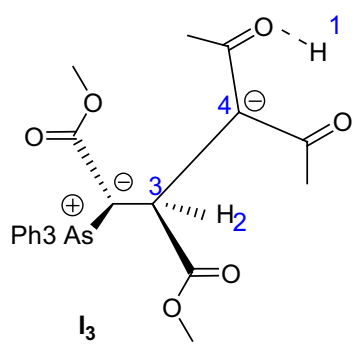

step4

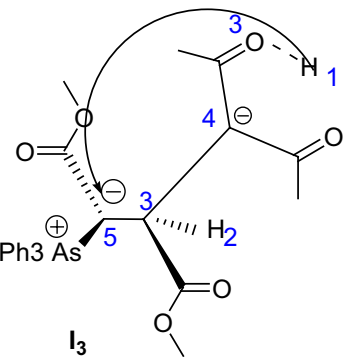

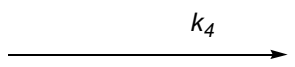

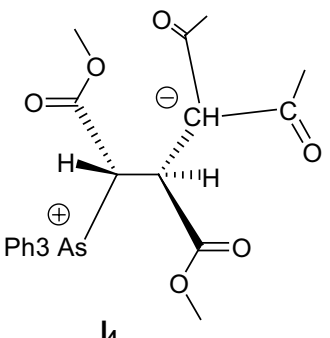

$\mathrm{I}_{4}$

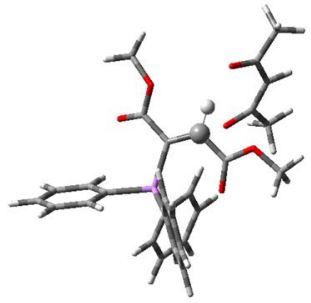

$\mathrm{I}_{2}$

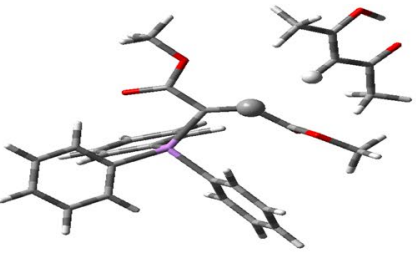

$\mathrm{I}_{1+}$ enol-ACAC $\mathrm{A}_{1}$

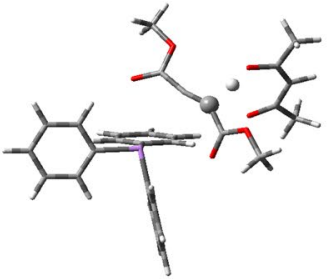

$\mathrm{TS}_{2}$

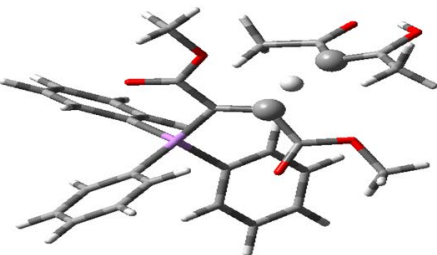

$\mathrm{TS}_{2}$

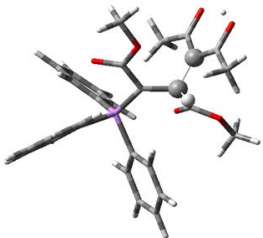

$\mathrm{I}_{3}$ the reaction through a difficult rout with highest total energy barrier, so the reaction can't proceed from the enol form and the mechanism regarding keto form of $A C A C$ is the right mechanism.
7. In the step $_{4}$, there are two possibilities for the protontransfer (a) 1, 2 proton-transfer and (b) 1, 3 protontransfer. In the case of "a", the product is an alkene, and in " $b$ " case, cyclopropane compound will be formed. 
Fig. 4 The optimized structures of the spices $\left(\mathrm{I}_{3}, \mathrm{TS}_{4 a}, \mathrm{I}_{3 \mathrm{a}}\right.$ $\mathrm{TS}_{4}, \mathrm{I}_{4}$ ) in step $\mathrm{s}_{4}$, in the case of enol form of ACAC in pathway B

Scheme 5 The proposed mechanism for the conversion of $\mathrm{I}_{3}$ keto form to enol and $\mathrm{I}_{4}$ intermediate

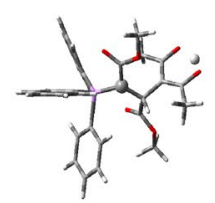

$\mathrm{I}_{3}$

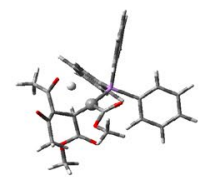

$\mathrm{TS}_{4 \mathrm{a}}$

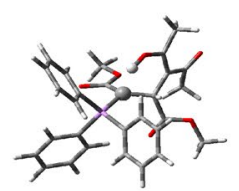

$\mathrm{I}_{3 \mathrm{a}}$

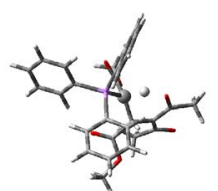

$\mathrm{TS}_{4}$

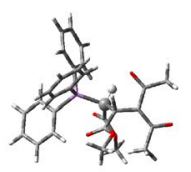

$\mathrm{I}_{4}$

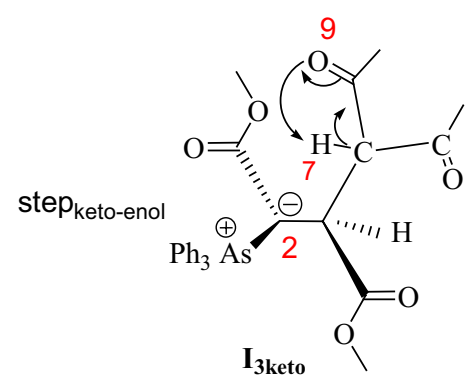

step $_{4}$

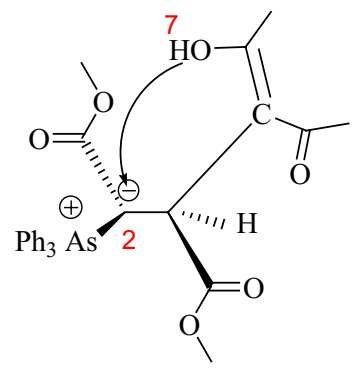

I 3 enol

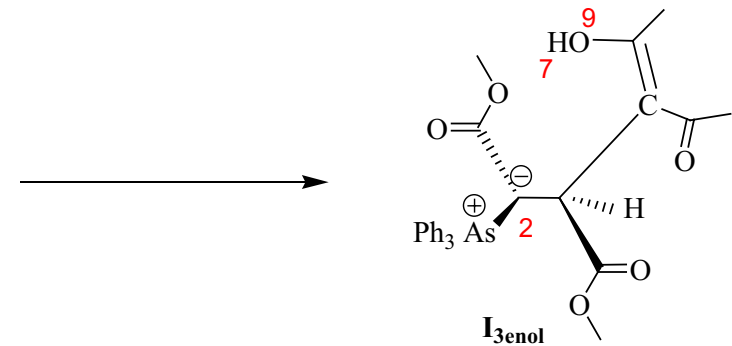

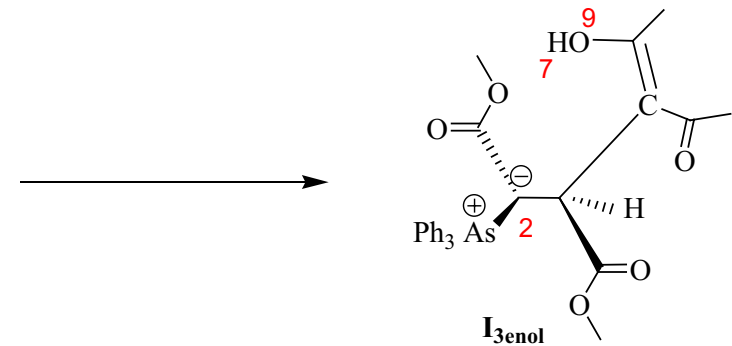

$[1,5]$ hydrogen-shift<smiles>COC(=O)C[C@H](C(=O)OC)[C@H]([13CH2]c1ccccc1)C(C)=O</smiles>

$\mathbf{I}_{4}$
The results exhibited that alkene thermodynamically is more stable than cyclopropane product but, the big energy barrier makes it unfavorable kinetically.

\section{Supplementary Information (SI)}

Scheme of reaction for each step ( $E$ or $Z$ form) and the potential energy profile included along with some tables in the supplementary information.

Acknowledgements This work was supported by the University of Sistan and Baluchestan.

\section{Compliance with ethical standards}

Conflict of interest The authors declare that they have no competing interests.

\section{References}

1. Lebel H, Marcoux JF, Molinaro C, Charette AB (2003) Stereoselective cyclopropanation reactions. Chem Rev 103:977
2. Neset S, Hope H, Undheim K (1997) Stereoselective synthesis of cyclopropane-1, 2-bis (glycine) derivatives. Tetrahedron 53:10459

3. Shen X, Liu Q, Zhang W, Hu J (2016) Stereoselective synthesis of (sulfonimidoyl) cyclopropanes with (R)-PhSO (NTs) $\mathrm{CH} 2 \mathrm{Cl}$ and $a, \beta$-unsaturated weinreb amides: tuning the of selectivity between $\mathrm{C}-\mathrm{Cl}$ and $\mathrm{C}-\mathrm{S}$ bond cleavage. Eur J Org Chem 5:906

4. Watson ID, Ritter S, Toste FD (2009) Asymmetric synthesis of medium-sized rings by intramolecular $\mathrm{Au}(\mathrm{I})$-catalyzed cyclopropanation. J Am Chem Soc 131:2056

5. Xie H, Zu L, Li H, Wang J, Wang W (2007) Organocatalytic enantioselective cascade Michael-alkylation reactions: Synthesis of chiral cyclopropanes and investigation of unexpected organocatalyzed stereoselective ring opening of cyclopropanes. J Am Chem Soc 129:10886

6. Tong W, Wang C, Zhao W, Chen J, Wu X, Zhang M, Deng H, Shao M, Ren Z, Cao W (2009) Facile, highly stereoselective synthesis of cyclopropyl benzoimidazoles via cyclopropanation of olefin with arsonium ylides. Synth Commun 39:3471

7. Macaev FZ, Malkov AV (2006) Use of monoterpenes, 3-carene and 2-carene, as synthons in the stereoselective synthesis of 2, 2-dimethyl-1, 3-disubstituted cyclopropanes. Tetrahedron 62:9

8. Zhao YH, Zheng CW, Zhao G, Cao WG (2008) Highly enantioselective tandem cyclopropanation/Wittig reaction of $a$, $\beta$-unsaturated aldehydes with arsonium ylides catalyzed by recyclable dendritic catalyst. Tetrahedron Asymmetry 19:701 
9. Maghsoodlou MT, Khorassani SM, Heydari R, Charati FR, Hazeri N, Lashkari M, Rostamizadeh M, Marandi G, Sobolev A, Makha M (2009) Highly stereoselective construction of functionalized cyclopropanes from the reaction between acetylenic esters and $\mathrm{C}-\mathrm{H}$ acids in the presence of triphenylarsine. Tetrahedron Lett 50:4439

10. Darijani M, Habibi-Khorassani SM, Shahraki M (2018) Effect of reactivity on kinetics and a mechanistic investigation of the reaction between dimethyl acetylenedicarboxylate and 1, 3-dicarbonyl compounds in the presence of a catalyst: a spectrophotometric approach. Prog React Kinet Mech 43:79

11. Darijani M, Habibi-Khorassani SM, Shahraki M (2015) A thermodynamic and kinetic insight into the pathways leading to a highly functionalized ketenimine: a computational study. Int J Chem Kinet Mech 47:751

12. Asheri O, Habibi-Khorassani SM, Shahraki M (2018) A study on the kinetics and mechanism of the one-pot formation of 3, 4, 5 -substituted furan-2 $(5 \mathrm{H})$-ones in the presence of lactic acid: effect of different substituents. Prog React Kinet Mech 43:286

13. Lee C, Yang W, Parr RG (1988) Development of the Colle-Salvetti correlation-energy formula into a functional of the electron density. Phys Rev B 37:785
14. Becke AD (1996) Density-functional thermochemistry IV. A new dynamical correlation functional and implications for exactexchange mixing. J Chem Phys 104:1040

15. Montgomery JA Jr, Ochterski JW, Petersson GA (1994) A complete basis set model chemistry. IV. An improved atomic pair natural orbital method. J Chem Phys 101:5900

16. Gonzalez C, Schlegel HB (1989) An improved algorithm for reaction path following. J Chem Phys 90:2154

17. Frisch MJ, Trucks GW, Schlegel HB, Scuseria GE, Robb MA, Cheeseman JR, Scalmani G, Barone V, Mennucci B, Petersson GA, Nakatsuji (2010) H Gaussian 09, revision A01. Gaussian Inc, Wallingford

Publisher's Note Springer Nature remains neutral with regard to jurisdictional claims in published maps and institutional affiliations. 